\title{
III CONGRESO NACIONAL DE CENTRO DEMOCRÁTICO Y SOCIAL
}

\author{
POR \\ M. " VICTORIA GARCIA-ATANCE \\ Profesora Titular de Derecho Constitucional \\ UNED
}

Durante los días 10 y 11 de febrero de 1990 se desarrolló en Torremolinos el Congreso del partido Centro Democrático y Social.

Fueron once las ponencias presentadas en el mismo.

Uno de los aspectos básicos de dicho Congreso, tal y como quedaría apuntado en la introducción de la ponencia política, fue el de análisis y reflexión de la situación política actual, tanto en relación a la política mundial así como de la política española, desde la posición del Centro Democrático y Social.

Desde esta perspectiva, el CDS efectuaría una valoración de la coyuntura por la que atraviesa el partido tras los resultados electorales de 1989.

En definitiva, el presente Congreso no deja de tener un cierto carácter de balance en la apreciación de los valores que ideológicamente propugna esta formación política y su inserción real en la sociedad mediante la acción política proyectada por aquél.

Esta acción politica lanzada desde el seno ideológico del CDS se traduce en dos pilares básicos: libertad e igualdad, para la consecución de determinados objetivos que se extienden en diferentes ámbitos, como se aprecia en la diversa indole de ponencias presentadas, a las cuales nos referimos a continuación.

\section{PONENCIA: DE POLÍTICA ECONÓMICA}

Éstà descendería a aspectos concretos como perfilar el peligro de España de configurar una economia con un déficit estructural de desarrollo 
respecto de los paises avanzados de la $\mathrm{CE}$, poco compatible con las demandas de la sociedad española que tiene como referencia precisamente aquel nivel de vida.

Otros aspectos clave como: tasa de inflación, déficit fiscal, producción-precios, salarios tasa, tasa de cambio de la peseta, efectos estructurales del sistema fiscal, efectos estructurales de la tasa de interés y poder adquisitivo serían expuestos en la misma.

\section{Política económica}

Esta parte giraría en torno a la propuesta de introducir un elemento corrector dentro del programa económico electoral. En este orden, la ponencia aduce la necesidad de adaptar el programa económico a tenor de las exigencias de los acuerdos formales que dentro y fuera de la CE se vayan produciendo como reacción al gigantesco proceso de cambio en curso de Europa.

Como premisas previas se propone en el ámbito de la CE:

1. Aceleración del proceso de integración monetaria de la CE conducente a la rápida creación de la Unión Monetaria.

2. Aceleración de la aprobación de la Carta Social Europea y aplicación de la misma bajo el criterio de subsidiariedad.

3. Apoyo, dentro de una robustecida CE, a la reunificación alemana.

Desde otra perspectiva aportan las sugerencias siguientes:

- Elevar el ahorro como factor esencial para mantener el equilibrio interno y externo.

- Incrementar la competitividad.

- Fomento de las infraestructuras y educación.

- Robustecimiento de la política social. 


\section{Politica fiscal}

En esta parte enfatizarían en unos determinados criterios tipo:

- La eficacia en la gestión del gasto.

- La eficacia económica como tal diseño de política y la consideración y respeto del contribuyente como ciudadano.

Desde esta óptica se perfilarian los cauces más idóneos para la consecución de esos objetivos.

\section{Politicas sectoriales}

Esta parte se vertebraria de forma bidimensional: desde el sector agrario y desde la pesca y Europa AZUL. lo que sigue:

El esquema seguido para el sector agrario se estructura en base a

1. Superación de la incompetencia y sectarismo.

2. Beligerancia económica del sector.

3. Vertebración del campo.

4. Sembrar futuro en el mundo rural.

5. Potenciación de la agro-industria.

6. Reto del mercado interior.

En materia de pesca, muy sumariamente puede mencionarse como conclusión adoptada la de la potenciación y plena participación de España en la Europa AZUL hasta el siglo XXI. 
II PONENCIA: POLITICA SOCIAL

Desde la consideración de que la política social es aún en el Estado contemporáneo un instrumento de apoyo al crecimiento económico y de integración social en el ámbito de la estabilidad política, se propusieron diversos criterios en torno a los siguientes aspectos que nos limitamos a enumerar:

1. Política social de protección: Seguridad social y acción social.

2. Política social de promoción: Fomento del empleo.

3. Política social de participación: Acción sindical y desarrollo laboral.

4. Política social de estímulo de iniciativas socio-económicas: Economia social.

III PONENCIA: POLITICAS BÁSICAS Y BIENESTAR SOCIAL

El texto presenta dos partes: cultura y sanidad.

En la primera de ellas, cultura, se plantean una serie de objetivos económicos, sociales, científicos y tecnológicos, como medios para conseguir determinados logros en la economia y bienestar social, distinguiendo entre objetivos económicos y sociales de los científicos y tecnológicos.

En la parte de la ponencia dedicada a la sanidad se diseñan los medios idóneos para cubrir el derecho a la salud de todos los ciudadanos en el plano de la igualdad.

IV PONENCIA: POLITICA ECOLÓGICA E INFRAESTRUCTURAS

Ésta se enfocaría desde una triple dimensión:

- Política ecológica. 
- Infraestructuras.

- Nuevos servicios.

Atendiendo al primer aspecto de los inmediatamente mencionados es preciso destacar la necesidad de una ética ecológica como premisa indispensable para proyectarla en un ámbito más genérico.

El segundo aspecto de infraestructuras se resuelve desde una cuádruple expectativa: infraestructura hidráulica, infraestructura energética, infraestructura forestal y, por último, infraestructura viaria.

La tercera categoría arriba mencionada se proyecta a su vez en torno a sectores clave como factores de equilibrio de nuestra balanza de pagos: turismo, vivienda y sueldo, tráfico y seguridad vial.

\section{PONENCIA: SERVICIOS INSTITUCIONALES BÁSICOS}

Ésta versaría sobre dos pilares fundamentales:

- Administración y función pública.

- Justicia.

En relación a la Administración se propugna una reforma en profundidad del actual entramado administrativo, partiendo de una serie de opciones, a fin de ofrecer un nuevo modelo de Administración pública.

En cuanto a la Justicia, partiendo de la premisa que predica nuestra Constitución al configurar un Estado Social de Derecho, se hace de todo punto imprescindible la garantía de la existencia del ejercicio efectivo de derechos y libertades, que a tal fin reside en los jueces y magistrados. Así, la tutela judicial efectiva ocupa un lugar básico en la concepción de nuestro orden constitucional. Desde esta valoración se hace imperativa la necesidad de un pacto de Estado para reformar las insuficiencias de la Administración de la Justicia, el cual pasó por reformar la LCGP. 


\section{PONENCIA: POLITICA EXTERIOR, PAZ Y DEFENSA}

El CDS entiende que un punto importante de la política internacional y de defensa consiste en propiciar la apertura de un foro de debate y negociación con vistas a la progresiva desmilitarización del Mediterráneo.

\section{PONENCIA: AUTONÓMICA}

Tras la constatación de la existencia de un proceso autonómico que adolece de graves deficiencias —unas de origen y otras sobrevenidas-, en esta ponencia autonómica se sugiere una serie de medidas para conseguir un Estado autonómico más armonioso y equilibrado. A tal fin se proponen las siguientes:

- Mayor equilibrio en la distribución de competencias.

- Modificación estructural de los Estatutos de Autonomia.

- Reducción burocrática de la Administración central.

- Reforma del sistema de financiación de las Comunidades Autónomas.

- Reforma del Senado.

- Participación de las Comunidades Autónomas en la política nacional.

VIII PONENCIA: DESARROLLO CONSTITUCIONAL

A pesar de que aunque las bases legales-constitucionales están establecidas en los articulos 14 y 35-1 de nuestra Constitución, para que el valor igualdad sea realizable se hace constatable una subsistencia discri- 
minatoria entre el varón y la mujer. Esta ponencia versa precisamente sobre el análisis de la realidad discriminatoria femenina.

IX PONENCIA: POLITICA DE JUVENTUD

Como contrapunto de la política del PSOE, carente de politica juvenil - como se afirma en esta ponencia-, el CDS propone una alternativa a esta situación, en base a desarrollar una administración al servicio de los jóvenes españoles.

\section{$X$ PONENCIA: DE ORGANIZACIÓN}

Parte del reconocimiento de una notable experiencia organizativa acumulada a lo largo de siete años de vida politica, habiéndose incrementado desde el anterior Congreso. Sin embargo, y a pesar de las múltiples medidas adoptadas a lo largo de este tiempo, el CDS se plantea la necesidad de una reflexión sobre los mayores problemas en este orden y los posibles cauces de solución aconsejables, incluidas las oportunas reformas estatutarias.

\section{PONENCIA: POLITICA}

Desde la aplicación práctica del principio de libertad e igualdad, el CDS presenta una alternativa de libertad entendida ésta en todas sus dimensiones, removiendo los obstáculos económicos, sociales y culturales que impiden a mucha gente el ejercicio real de la libertad. Siendo libertad e igualdad compromisos éticos irrenunciables, habrá que atender a las necesidades sociales más acuciantes, para que, en una igualdad de oportunidades y respetando la libertad individual, se logre el Estado de bienestar.

Reconocimiento, por otra parte, de la necesidad absoluta y prioritaria de profundizar en el proyecto político del CDS, teniendo como norte libertad e igualdad, perfilando ante la sociedad española su identidad y persona- 
lidad, lo que ha de traducirse necesariamente en una acción politica sin excluir la posibilidad de acuerdos que contribuyan a la implantación en la sociedad del cuadro de valores que le son propios.

Con esta última Ponencia Política, se daria por finalizado el Congreso del CDS que tuvo como eje, tal y como hemos venido afirmando, la plasmación práctica en un proyecto político del principio de libertad e igualdad en la sociedad española. 